\title{
Article
}

\section{Soil hydrology process and Rational Use of Soil Water in De- sert Regions}

\author{
Zhongsheng guo ${ }^{1.2, *}$
}

\author{
1 Institute of Soil and Water Conservation, Northwestern A \& F University, Yangling, China \\ 2 . Institute of Soil and Water Conservation, CAS \& MWR, Yangling, China \\ * Correspondence: zhongshengguo@sohu.com; Tel.: +86-29-87012411
}

\begin{abstract}
There is a balanced plant-water relationship in the primary vegetation of desert area. With the increase of population and social development in desert areas, people's need for forest vegetation ecosystem's goods and service have been changed. To meet the growing demand for plant community goods and services, more original vegetation has been changed into non-native vegetation such as in China loess plateau. However, with the plant growth, sometime soil drying happens and then becomes gradually serious with times in most of desert regions. Serious drying of soil eventually results in soil quality degradation, vegetation decline and crop failure, which influence the produce and supply of forest vegetation goods and service in market in dry year or waste of soil water resources in wet year, which wastes precious nature resources. In order to use soil water rationally, soil water must be used in sustainable way and plant-water relationship have to be regulated on Soil Water Carrying Capacity for Vegetation in the key period of plant water relationship regulation, to carry out sustainable use of nature resources, high-quality sustainable development of forest and grass or high-quality produce of fruit and crop in desert regions.
\end{abstract}

Keywords: infiltration; run off; deep leakage; Soil water; plant growth; Use Limit of Soil Water Resource by plants; Carrying Capacity of Soil Moisture for Vegetation; key period of plant water relationship regulation; rational use of water resources

\section{Introduction}

There is a balanced plant-water relationship in the primary vegetation of desert area. With the increase of population and social development in desert areas, people's need for forest vegetation ecosystem's goods and service have been changed. To meet the increasing needs of people for some special goods and service and diversity that original vegetation cannot produced, more and more original vegetation has been changed into nonnative forest land and grassland and cropland in the water limited areas, such as in China loess plateau (Guo and Shao,2013). The goal of afforestation is to increase vegetation cover while increasing canopy interception, soil water consumption, the yield and services of plant community systems and changing soil hydrological characteristics such as run off, soil water consumption and deep leakage.

Soil water only be used by plant root, and soil water in most of the water-limited regions only come from precipitation. With the growth of plant, plant canopy closure and root system develop, and soil drying appeared and sometime soil drying becomes gradually serious with increasing times in most of forest land and grassland and cropland in desert regions, such as in China loess plateau because these in desert regions feature low and highly variable seasonal and annual rainfall without irrigation. Serious drying of soil eventually happened in most of non-native forest land and grassland and cropland, and then result in soil degradation, vegetation decline and agriculture failure.

In order to solve these problems, plant-water relationship have to be regulated on Soil Moisture Carrying Capacity for Vegetation (SMCCV) (Guo et al,2002, Shao,2013 in the key regulation period when the Soil Water storage in the maximal infiltration depth (MID) is equal to the Use Limit of Soil Moisture Resources by Plant (ULSMRP). The purpose of the paper is to introduce the theory of the ULSWRP and Carrying Capacity of Soil Moisture for Vegetation (CCSMV) to carry out rational use of soil water and promote the high-quality and sustainable development of forest, grass land and crop in desert regions. 


\section{Materials and Methods}

Study preparation

Within the non-native forest such as caragana stand at the similar site conditions, five similar 100 $\mathrm{m}^{2}\left(5 \mathrm{~m} \times 20 \mathrm{~m}=100 \mathrm{~m}^{2}\right)$ plots with the same conditions, including slope gradient, see table 1,slope direction, slope position and vegetation type and soil, were prepared. The planting density of the 16-year-old caragana (Caragana korshinskii) shrubland was 87 shrubs per $100 \mathrm{~m}^{2}$. One experimental plot kept this density while the other four density were reduced by cutting away the aboveground caragana plant to establish five field experimental plots with different planting densities of 87, 71, 51, 32 and 16 shrubs per $100 \mathrm{~m}^{2}$. The experiment lasted from 2002 to 2020, caragana korshinskii stems that grew from the base of the cut shrubs were cut when they had grown to a height of about $5 \mathrm{~cm}$ to maintain the specified planting density.

Table 1 Slope and canopy projection area of Caragana korshinkii at different planting densities

(shrubs $100 \mathrm{~m}^{2}$ )

\begin{tabular}{|c|c|c|c|c|c|}
\hline $\begin{array}{c}\text { planting } \\
\text { density }\end{array}$ & $\mathbf{8 7}$ & $\mathbf{7 1}$ & $\mathbf{5 1}$ & $\mathbf{3 2}$ & $\mathbf{1 6}$ \\
\hline $\begin{array}{c}\text { Slope gradi- } \\
\text { ent }\left(^{\circ}\right)\end{array}$ & 7.9 & 7.8 & 8.5 & 7.7 & 7 \\
\hline $\begin{array}{c}\text { Projection } \\
\text { area }(\mathrm{m} 2)\end{array}$ & 99.2 & 99.1 & 99.1 & 99.3 & 99.4 \\
\hline
\end{tabular}

Another five similar $100 \mathrm{~m}^{2}$ plots were prepared at the same slope, soil. Different sowing seed amount was sowed with $0.5,1.0,1.5$ and $2.0 \mathrm{~kg}$ per $100 \mathrm{~m}^{2}$,on 24 June,2002 to get young caragana stand. And the $1 \mathrm{~m} \times 1 \mathrm{~m}$ quadrants were used to investigate caragana planting density at each plot.

Canopies interception measurements

The rainfall data in study site from 1983 up to 2001 were obtained from the Shanhuang Eco-experiment monitoring station, located at about $50 \mathrm{~m}$ away from the study area. Three standard rain gauges with a diameter of $20 \mathrm{~cm}$ were placed in the open space near each plot to measure rainfall outside of Caragana shrub land. A further 2 to 4 shorter rain gauges with the same diameter were placed under the sample caragana shrubs in the plots to measure throughfall. Canopy interception was measured during rainfall events. Canopy interception (CI) of a single caragana canopy equaled the difference between the rainfall measured in the areas without shrubs $\left(\mathrm{P}_{2}\right)$ and that measured beneath the canopy of the caragana shrubs $\left(\mathrm{P}_{1}\right)$; i.e., $\mathrm{CI}=\mathrm{P} 2-\mathrm{P} 1$. The rate of canopy interception in a plot $(\mathrm{Cp})$ for a specific growth stage is obtained from: $\mathrm{Cp}=\mathrm{CI} \times \mathrm{CD}$, (guo 2020; Guo and Shao, 2004, 2013).

\section{Runoff measurement}

One upper edge and two edges of the plot are enclosed by concrete slabs, $50 \mathrm{~cm}$ high and $30 \mathrm{~cm}$ deep, forming a $100 \mathrm{~m}^{2}(5 \mathrm{~m} \times 20 \mathrm{~m})$ runoff plot. Slope gradient is given in table 1 . Runoff is channelled from the lower end of the plot into a covered collection bin. Record the runoff after each rain fall.

\section{Root distribution}

A shrub, to be used as a sample plant with about mean height and basic diameter of the caragana shrubs near the plant plot, was selected. The aboveground parts of the caragana shrub were cut and a hole was dug near the base of the caragana shrub $(1 \mathrm{~m} \times 1 \mathrm{~m}$ in area, and $5 \mathrm{~m}$ deep). Average root diameter and biomass were mearsured for soil depths of 0 to $10 \mathrm{~cm}, 10$ to $50 \mathrm{~cm}, 50$ to $100 \mathrm{~cm}, 100$ to $200 \mathrm{~cm}, 200$ to $300 \mathrm{~cm}, 300$ to $400 \mathrm{~cm}$, and 400 to $500 \mathrm{~cm}$. 
In each runoff plot, the dry biomass of the herbaceous plants under the shrubs was investigated from sample samples, which were cut and collected from four $1 \mathrm{~m} \times 1 \mathrm{~m}$ quadrants plot and dried at $105^{\circ} \mathrm{C}$, and a visual assessment of the overall coverage area of these plants. Plots were measured,and the survival rate is estimated in the following spring.

\section{Soil water measurement}

Two 4-metre-long aluminum tubes were inserted into the soil in the center of each test area with a contour distance of 2 meters between them. A neutron detector, CNC503A (DR), made by Beijing Nuclear Instrument Company in Beijing, was used for monitoring the field soil water content. Neutron detector calibration was performed on the soils of the study site using standard methods (Hauser, 1984). The neutron detector detects slow neutrons, which are linearly related to soil moisture content (Evett et al 2012; Guo and Shao 2013). The calibration equation was:

$\mathrm{A}=55.76 \mathrm{~B}+1.89$

Where, $\mathrm{A}$ is the percentage of soil volumetric water content $(\%)$, and $\mathrm{B}$ is the ratio of the neutron count in soil to the standard count in water. Start at a depth of $5 \mathrm{~cm}$ and measure a depth of $4 \mathrm{~m}$ every 15 days, increasing by $20 \mathrm{~cm}$. In addition to $5 \mathrm{~cm}$ depth representing $10 \mathrm{~cm}$ of the soil surface, the soil water content obtained at each measured depth represents the soil layer $\pm 10 \mathrm{~cm}$ deep at the measured point. The neutron count lasts 16 seconds. In addition, we measured soil moisture content before and after rainfall. In addition, soil water content in red plum apricot plantation was measured in 2017 to 2020 , and alfafa grass land in 2011-2013.

The two-curve method is used to determine the rainfall infiltration depth of a rainfall event (Guo, 2004, 2020). The recharge depth is the distance from the surface of the soil profile to the intersection of the two vertical soil moisture curves before a rain event and after the rain event. There is no groundwater effect, and it is assumed that there is no lateral flow, and the water consumption of planting plants during heavy rainfall is negligible (Guo \& Li, 2009).

Soil moisture supply (SMS) was calculated from:

$\mathrm{SMS}=\mathrm{P}_{2}-\mathrm{CI}-\mathrm{RF}$

Where, $\mathrm{P}_{2}$ expresses the sum of precipitation outside shrub and CI canopies interception and RF expresses runoff $(\mathrm{mm})$.

Soil moisture consumption (SMC) was estimated from:

$\mathrm{SMC}=\mathrm{W}_{1}-\mathrm{W}_{2}+\mathrm{SMS}$

Where $\mathrm{W}_{1}$ expresses initial soil water resources in $\mathrm{mm}$, and $\mathrm{W}_{2}$ final soil water resources in $\mathrm{mm}$.

The pit was dug at the non-native forest such as caragana, and alfalfa grass samples were collected at the experimental sites for use in investigating soil profiles. The sampling pit dimensions were $1 \mathrm{~m}^{2} \times 4 \mathrm{~m}$ depth, and they were dug on the Caragana shrubland in September 2012 and in the alfalfa grassland in 2015 . The undisturbed soil samples were collected in triplicate at depths of 0 to $5 \mathrm{~cm}, 20$ to $25 \mathrm{~cm}, 40$ to $45 \mathrm{~cm}, 80$ to $85 \mathrm{~cm}, 120$ to $125 \mathrm{~cm}, 160$ to $165 \mathrm{~cm}, 200$ to $205 \mathrm{~cm}$, 240 to 245,320 to 325 and 380 to $385 \mathrm{~cm}$ with cutting rings $(5 \mathrm{~cm}$ high, $5 \mathrm{~cm}$ inner diameter, and $100 \mathrm{~cm} 3$ volume), and the excess soil at the openings on both sides of the ring were cut using a sharp knife, sealed, and transported to the laboratory for use in subsequent analyses.

\section{Moisture content measurement at different soil suctions}

The cutting ring was used to measure the soil bulk density, total porosity, saturation moisture content and capillary porosity. The core samples (soil sample undisturbed) collected were used with cutting rings to measure the soil bulk density, noncapillary porosity and capillary porosity. The bulk density was determined by oven-drying the cores at $105-110^{\circ} \mathrm{C}$, and the total porosity was calculated as 1-bulk density/soil particles density, assuming that the density of soil particles was $2.65 \mathrm{~g} / \mathrm{cm}^{3}$. Capillary porosity was equal to the difference between total porosity and noncapillary porosity. Organic content was measured using the Potassium dichromate volumetric method. A Laser granulometer is commonly used for the analysis of the grain sizes of marine 
sediments. Soil particle sizes were measured using a master sizer 2000 laser particle analyser (Malvern Instruments Ltd., Malvern, UK) and grain size was graded based on the United States Department of Agriculture classification system for particle sizes. Soil water concentrations at different soil suctions $(0.1,0.2,0.4,0.6,0.8,1.0,2.0,4.0,6.0,8.0 \mathrm{bar}, 1 \mathrm{bar}=0.1 \mathrm{MPa})$ were measured using a Hitachi centrifuge (Hitachi Instruments Inc., Tokyo, Japan). soil moisture characteristic curve was established to determine wilting coefficient when soil suction equal 15 bar.

Estimating method for the critical period of plant-water relationship the regulation

When the soil moisture resources in the MID equal the ULSMRP on a day, the moment is the starting time to regulate the relationship between soil water and plant growth (Guo \& Li, 2009). From the starting time, according to the forcasting SWCCV, which was estimated by the precipitation, soil water supply and single plant consumption in the key period of plant water relationship regulation, plants $\mathrm{A}, \mathrm{A}=\mathrm{P}-\mathrm{VCC}$, were removed at the maximum experimental planting density, ensuring maximum experimental planting density is more than soil water carrying capacity for vegetation at different situation because soil water carrying capacity for vegetation change with precipitation, which is the main source of soil water resources in water-limited regions. The plant-water relationship was continuously day by day adjusted in the same manner, ensuring an even distribution of existing plants. where, $\mathrm{P}$ is the preserved plant density and VCC is carrying capacity and then the plant growth and soil water was investigated in the thinned plot and unthinned plot. If the plant density is adjusted on day I, the plant-water relationship is normal and the plant grows healthily, and the plant density is adjusted on day I +1 , the plant growth is unhealthy, the vegetation declines and the crops fail, the duration day I is the critical period for the regulation of plant-water relationship.

\section{Results}

\subsection{Soil water resources}

Soil Water Resources is soil water storage in the soil, which are renewable water resources and a components of water resources. The concept of soil water resources emerged in 1986 (Budagovski, 1986) after the concept of overall soil moistening (Lvovich, 1980). There are generalized soil water resources and narrow sense soil water resources. Generalized soil water resources could be defined as the water stored in the soil from the surface soil to the water table, commonly used in geology or architecture, and narrow soil water resources is the soil water storage in the root zone soil, commonly used in forestry, grass or agriculture. Soil water resources are renewable water resources and are components of water resources (Guo, 2011, 2014).

In addition, there is a dynamic soil water resources, which is the antecedent soil water resources plus the soil water supply from precipitation in the critical period of plantwater relationship the regulation, the growing season for deciduous plants, or over a year for evergreen plants (Guo, 2011). Soil water resources change with rainfall, run off, soil evaporation, plant transpiration, deep leakage and soil water moving.

\subsection{Root water absorption}

Root is the most important organ for terrestrial life plant to suck soil water even though stoma in a leaf and a stem can suck a little water when air humidity is high such as raining. So, root distribution is the most important index to characterize soil water deficit.

Root distribution can be investigated by soil-pit method. For example, the most part of caragana root biomass distributed in the 0 to $200 \mathrm{~cm}$ soil layer even though the root extends to 5.0m in16-year-old shrub Caragana korshinskii shrub in semi-arid hilly region of Loess Plateau (Guyuan, China), see fig.1 (Guo and Shao, 2013), which is more than maximum infiltration depth, The Soil water can be used by plants. 


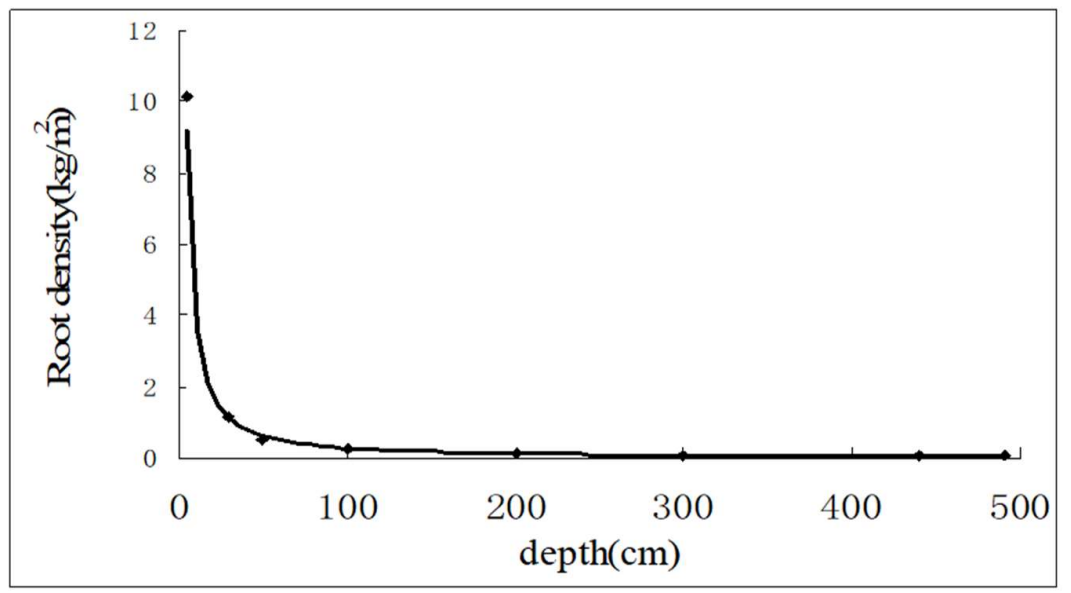

Fig. 1 Root distribution of 16-year-old shrub Caragana korshinskii shrub in semi-arid hilly region of Loess Plateau.

Plants do not continue to suck soil water. If the soil moisture supply is smaller than soil moisture consumption and the soil water resources will reduce to the Lethal soil water resources (LSWR), which is the soil water storage when soil water content in the root zone soil is equal to wilting conference, one day. When soil moisture resources equal the LSWR and there is no timely soil moisture supply from rain, the plant will die because, at this time the plantavailable soil moisture in the root zone soil is used up.

\subsection{Use Limit of Soil Moisture Resource by Plants (ULSMRP)}

Soil water can only be used by plant roots, and the use of soil water resources by plants must be limited because Soil water mainly come from precipitation is limited with big seasonal and yearly change and soil moisture only come from precipitation in most of the water-limited regions. The control degree can be expressed by Use Limit of Soil Moisture Resource by Plants (ULSMRP) (Guo, 2009, 2014,2020). SWRULP is use limit of soil moisture resources by Plants, which can be defined as the soil moisture storage in the maximal infiltration depth (MID) in which soil moisture content is equal to wilting coefficient. The wilting coefficient is expressed by the wilting coefficient of indicator plant because the wilting coefficient is changed with different plants and many single species of plants live together to form a plant population or many different species of plants live together to form a plants communication and then use solar radiation and soil moisture to produce goods and service. Indicator plants of natural vegetation are established species, and indicator plant of non-native trees or grasses for plantation is principal or purpose species. For example, the indicator plant of caragana shrubland is caragana even if there are some other species of herbaceous plants growing under the shrubs included Heteropappus attaicus, Stipa bungeana, Lespedeza davurica, Artemisia giraldii, and Thymus mongolicus (Guo \& Shao, 2013).

Soil moisture resources can be defined as the soil moisture storage in root soil zone, which is the best indicator to express soil moisture state because plant roots distributed vertically in the root soil zone and suck soil moisture from the root soil zone. Along with plant sucking soil water, soil water content reduces in the root soil zone, and moisture stress is increasing, the soil moisture resources and the power of plant self- regulation through stomatal opening are limited. So the degree plant root suck soil moisture must be limited in the most of moisture -limited regions. The limit is expressed by Use Limit of Soil Moisture Resource by plants (ULSMRP) (Guo,2010).

ULSMRP can be defined as the soil moisture storage in the MID in which the soil moisture content of each soil layer is equal to the withering coefficient. The wilting coefficient of a plant community is expressed by the wilting coefficient of indicator plant. 
Some plant communities are formed by a single plant species and others are formed by many plant species live together and form the community to use space resources, soil water resources or soil nutrient resources. Although any one species in a plant community can express ULSMRP or CCSMV in this situation in theory, but the different plant species differ in their positions and roles in the community. Constructive species for natural vegetation and principal or purpose species of trees or grasses are selected drought resistant plant species. Principal species are the main afforestation tree species and account for the majority of the trees planted in a region, and purpose species of trees or grasses are those cultured or managed by people in a region such as salix mongolica and Haloxylon ammodendron. Generally, principal species of trees or grasses are also purpose species in a region, and corn is purpose species in corn land because weeding and plastic mulching.

\subsection{Infiltration and maximum infiltration depth}

Maximum infiltration depth is the most important indicator for estimating the Soil Moisture Resources Use Limit by Plants. Infiltration depth includes the infiltration depth for one rain and maximum infiltration depth because there is a cumulative infiltration such as in China loess plateau because loess clay adsorption and continuous rainfall. If you investigate the change in soil moisture content with soil depth before a rain according to the weather report and the change in soil moisture content with soil depth after the rain, the infiltration depth for one rain event can be determined by the two curve method - the infiltration depth is equal to the distance from the land surface to the crossover point between the two adjacent vertical soil moisture distribution curves with soil depth before a rain and after the rain event, see fig.2. The MID will occur after a continuous heavy rainfall

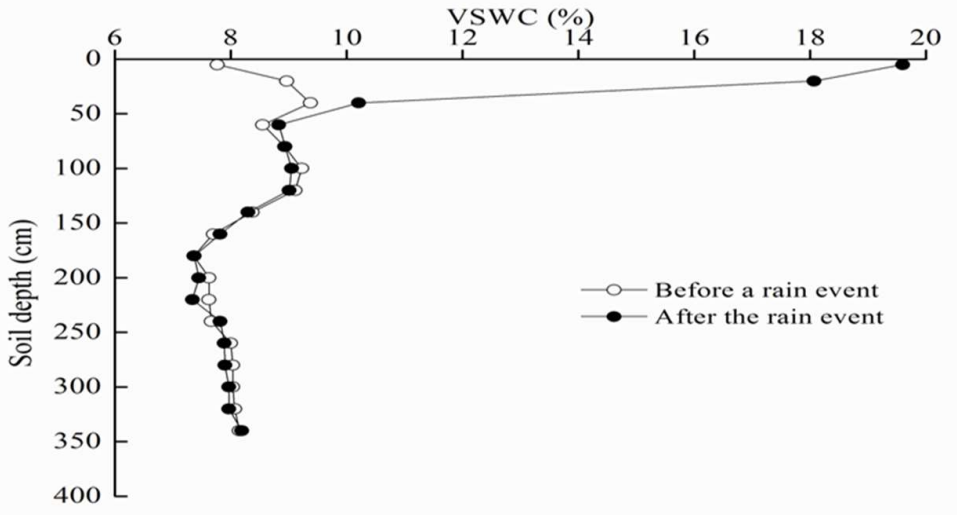

Fig. 2 The vertical changes of soil moisture with increasing soil depth after and before a rainfall event in caragana korshinskii shrubland.

event or in a long-term infiltration process and can be determined by a series of two curve methods, see fig.3 (Guo, 2020). Under nature condition, there is a maximal infiltration depth. Even generally root distribution depth in the water-limited regions is more than maximal infiltration depth and take moisture from the soil layers below the wetting front depth, but the soil moisture mainly from the precipitation and the water cannot be recover once soil moisture content in the soil layers below the wetting front depth is smaller than wilting coefficient, which will influence plant growth severely and cause vegetation decline. and, and SWRULP is $222.8 \mathrm{~mm}$ and LSWR is $405.7 \mathrm{~mm}$ in 16-year-old Caragana shrubland in the semiarid loess hilly region of China.

Infiltration depth after and before a rainfall event can be determined by the twocurve method discovered in 2003 and named in 2015. The infiltration depth isequal to the 
distance from the surface to the crossover point between the two adjacent soil moisture distribution curves of soil moisture with soil depth before and after the rain event, see Figure 2.

In nature, infiltration process includes the MID will occur after a continuous heavy rainfall event and a long-term cumulative infiltration process, and can be determined by a series of two-curve methods, see figure 2 . The maximum infiltration depth is $290 \mathrm{~cm}$, see figure 3 in 16-years-old Caragana and red plum apricot plantation (Guo \& Shao, 2009, Guo, 2020)

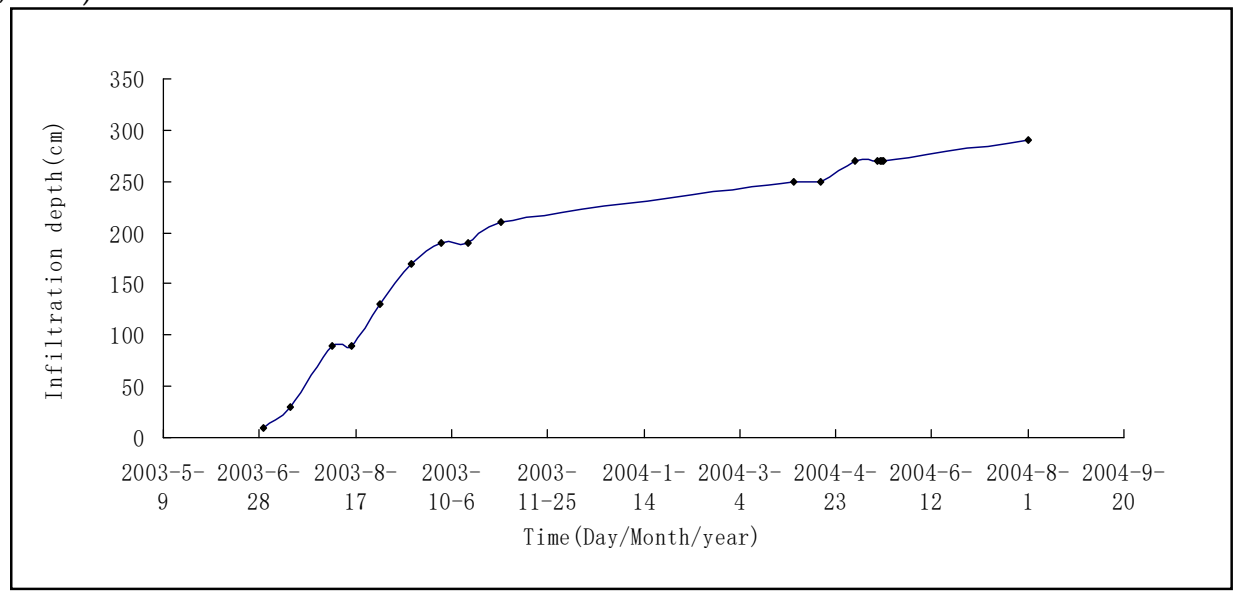

Fig. 3 Change of cumulative infiltration process with increasing time in Caragana Korshinskii shrubland in the semiarid and loess hilly region (Guyuan, China).

\subsection{Carrying Capacity}

Nature Resource is limitation, which limits a maximal size that a population can safely obtain in desert soil. Carrying capacity is the best indicator to express creature-environment relation and the core issue for high quality and sustainable development.

After sustainable development (1987), the term carrying capacity was first used by range managers (Price, 1999) and U.S. Department of Agriculture researchers (Young, 1995). Following the 1920 formulation of the logistics equation by Raymond Pearl and Lowell J. Eugene Odum (1953) relates the carrying capacity term to the constant k, see equation 1:

$$
\frac{d N(t)}{d t}=r N(t)\left(\frac{K-N(t)}{K}\right) \quad \mathrm{t}>0
$$

Where $N(t)$ is density at time $t$, the population per unit area at time $t, r$ is the intrinsic growth rate, $r>0$ and $\mathrm{K}$ is an asymptote (the carrying capacity) with $\mathrm{K}>0$ (Guo 2019).

The maximal plant population can be expressed by carrying capacity, which is the maximum population that nature resources carry plant population.

\subsection{Carrying Capacity of Soil Water for Vegetation}

Vegetation carrying capacity is the ability of land to support vegetation. Because Vegetation includes different plant communities that changes with plant species. To solve serious drying of soil because the serious drying of soil eventually results in soil quality degradation, vegetation quality decline and crop failure, the conception of carrying capacity of soil Moisture for vegetation appeared.

The ability of Soil Moisture Resources to carry vegetation is limited because soil water resources is limitation. The limitation can be expressed by the Carrying Capacity of Soil Moisture for Vegetation (CCSMV). The CCSMV is first appeared in 2000 (Guo, et al., 2002). It can be defined as the highest density or population quantity (absolute index) of indicator plant in a plant community when soil moisture consumption equals soil moisture supply in the root-zone soil in a given period, especially the key period of regulating the plant water relationship, which is the minimum death day. SWCCV can be determined 
by classical carrying capacity model, that is to say, CCSMV is equal to available soil water resources be divided by single plant moisture demand or the soil water- plant density model. If we established a series of density experiment at the same condition and the same plot areas and measured the precipitation, throughfall, runoff, deep leakage and estimated the soil moisture supply and soil moisture consumption under different density in key period of regulating between soil moisture and plant growth, and then establishes the equations between plant density and soil moisture supply and soil moisture consumption respectively. Soil moisture supply reduces with increased planting density; and the relationship between soil moisture consumption and population quantity or density can be described by a parabolic equation (Figure. 4). CCSMV can be estimated by combining and solving the simultaneous equations (Guo \& Shao, 2004; Guo 2021).

\subsection{The key period of regulating plant water relationship}

The plant water relationship in a growing period or year can be divided into different period. The first stage ranges from sowing or dormancy to germination, which is the period of insensitivity or dormancy. After preparing the ground, fertilizing the fields, planting or sowing seed, the soil water content is high and plant water relation is good. At this point, soil moisture is not the limiting factor for plant growth. The second stage is the period from germination to fully expansion of leaf. At this point, the force of soil moisture on plant growth increase. When the soil moisture resources in the MID is equal to the SWRULP, the instantaneous time is called the starting time to consider regulating the relationship between plants and water (Guo and Li, 2009). And then plant-water relationship goes into key period of regulating soil moisture and plant growth relationship. The key period of plant water relationship regulation is the most important period, which decided the maximum output and benefit of forest and vegetation. If the planting density is more than the CCSMV in this period, the relationship between soil water and plant growth must be regulated based on the CCSMV, especially the CCSMV in the key period of regulating the relationship between soil water and plant growth.

The key period of regulating the relationship between soil water and plant growth can be determined by the thinning method. We can establish maximal planting density, that is the planting density of indicator plant when the precipitation is maximum because the precipitation in water-limited regions changes great. For example, the precipitation of Guyuan ecoexperiment station ranges from $284.3 \mathrm{~mm}$ in 1986 to $634.7 \mathrm{~mm}$ in 1984 in the semiarid loess hilly region (Guo and Shao, 2013).

When the soil moisture resources in the MID equals the ULSWRP on a day, the moment is the starting time to regulate the relationship between soil water and plant growth (Guo \& Li, 2009). From the starting time, according to according to the forcasting CCSMV estimated by the precipitation, soil water supply and single plant consumption in the key period of plant Moisture relationship regulation, plants $\mathrm{A}, \mathrm{A}=\mathrm{P}-\mathrm{VCC}$, were removed at the maximum experimental planting density and the plant- moisture relationship was continuously day-by-day adjusted in the same manner, where, $\mathrm{P}$ is the preserved plant density and VCC is CCSMV and then the plant growth and soil water was investigated in the thinned plot and un-thinned plot. If the plant density is adjusted on day I, the plant-water relationship is normal and the plant grows healthily, and the plant density is adjusted on day I +1 , the plant growth is unhealthy, which cause the vegetation declines and the crops failure, the duration day I is the critical period for the regulation of plant-water relationship. If the soil water resources were more than the SWRULP because of rain event, the experiment was stop, which showing that the plant-water relationship has not need to be regulated in the year.

If from the starting time and the precipitation, run off, the changes of soil water content with vertical before and after the rain event and deep leakage in different plant density plot, the soil water supply and soil water consumption was estimated, the forcasting SWCCV can be test according to the relationship between plant density and soil moisture supply and the relationship between plant density and soil moisture consumption in the key period of regulating between soil moisture and plant growth. Simultaneous equations to solve, carrying capacity of soil moisture for vegetation is the positive root, see Fig.4. 


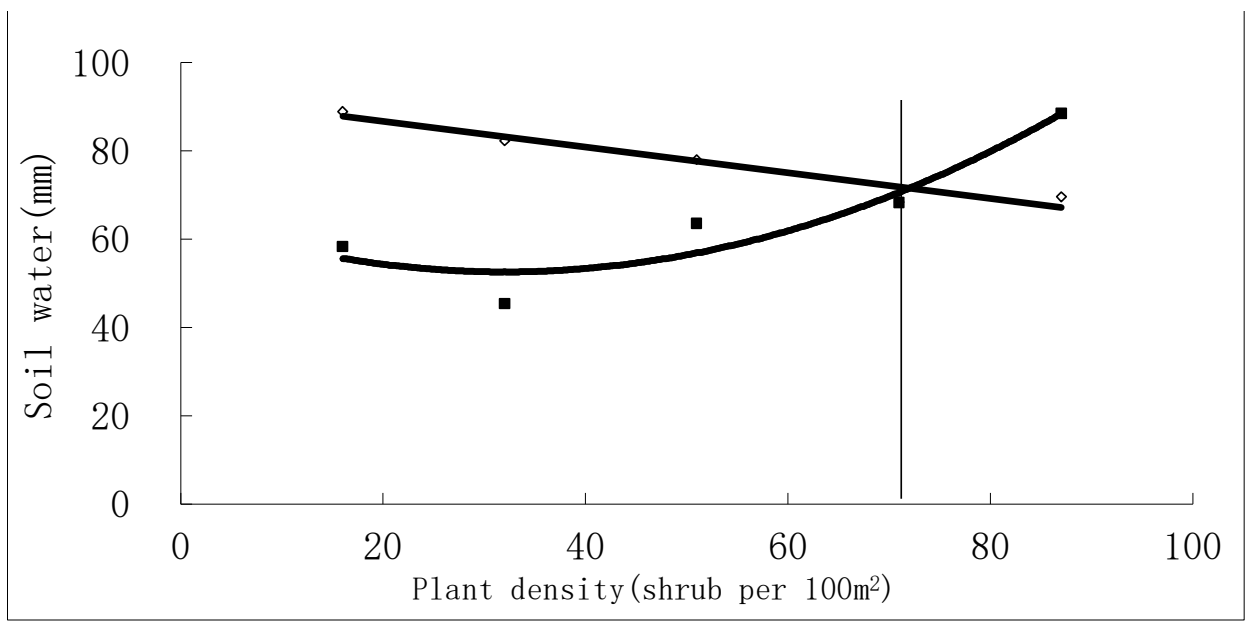

Fig. 4 The changes of soil moisture supply (Hollow circle) or soil moisture consumption (Solid square) with plant density in the key period of plant moisture relationship regulation of 18-years-old Caragana shrubland in the semiarid loess hilly region.the crosspoint is

The maximum yield and service will be obtained, see fig.5.

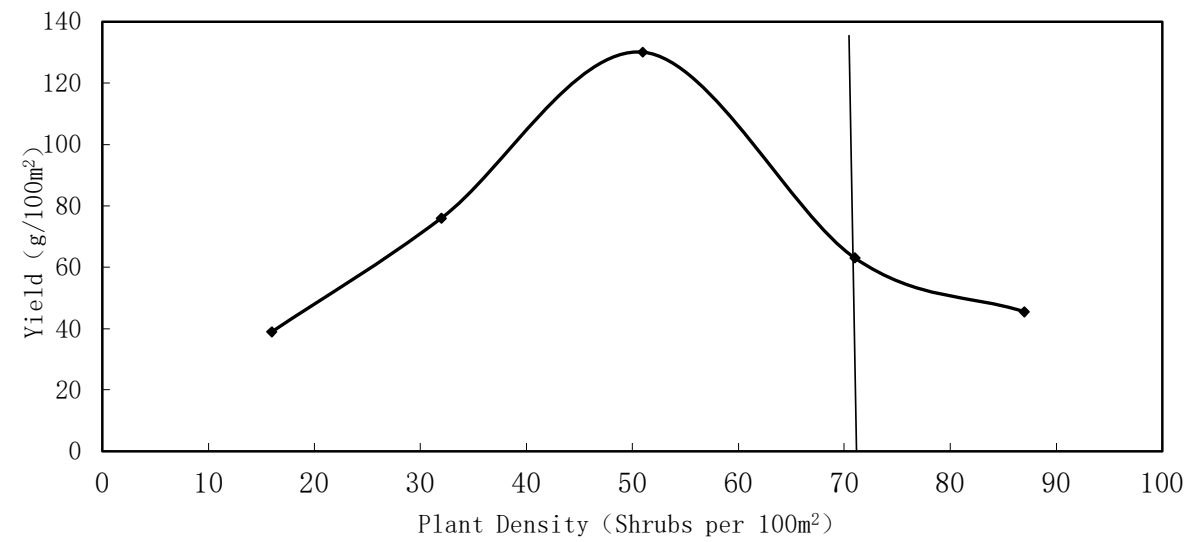

Fig.5 The relationship between plant density,carrying capacity and caragana seed yield in the semiarid loess hilly region

\section{Discussion}

There is a balanced plant-water relationship in the primary vegetation of desert area because the plant conductivity, canopy interception, and soil moisture use depth and soil moisture consumption are low, and soil moisture supply is bigger. There is not serious soil drought and soil degradation. With the increase of population and social development in desert areas, people's need for forest vegetation ecosystem's goods and service have been changed. To meet the increasing needs of people for some special goods and service and diversity that original vegetation cannot produced, more and more original vegetation has been changed into nonnative forest land and grassland and cropland in the moisture -limited regions, which increase canopy interception, soil water use depth and soil water consumption and changed soil hydrological characteristics, but the nonnative forest land and grassland and cropland has a lower capacity to regulate the soil water and plant growth, which will result vegetation decline and crop failure in dry years or waste of soil water resources. So the plant water relationship must be regulated on carrying capacity 
of soil water for vegetation when the soil moisture resources in the maximum infiltration depth equal Use Limit of Soil Moisture Resources by plants and the duration of severe soil drying is more than key period of plant water relationship regulation. This action not only solve soil quality degradation, vegetation decline and crop failure but also ensure sustainable use of soil moisture resources, realize high-quality and sustainable management of forest, and fruit and crop sustainable produce. For example, In the semiarid loess hilly region of the 17-year-old Caragana forest, serious soil drought and soil quality degradation occurred, leading to the early defoliation of Caragana, because the plant density of 87 plants per 100 square meters is greater than the soil water bearing capacity of 72 bushes per $100 \mathrm{~m}^{2}$. When the rainy season comes, the canopy interception disappears, which affects Maximum benefits of Caragana korshinskii forest for soil and water conservation before rain season appeared on August,5, 2003

\section{Conclusion}

Soil water resource is water stored in soil space, and it is a part of water resource. Only plants can take advantage of soil moisture otherwise soil water resource will be wasted. Non-native vegetation changes the soil hydrology process, plant water relationship, sometime soil drying happened and becomes gradually serious in non-native vegetation. Serious drying of soil eventually results in soil quality degradation, vegetation decline and crop failure, which influence the production and supply of forest vegetation products and services on the market. The soil moisture resources must be used in sustainable way in desert regions. If the duration of severe soil drying is more than the key period of plant water relationship regulation, plant-water relationship must be regulated on Carrying Capacity of Soil Water for Vegetation in the key regulation period of the plant water relationship, to carry out sustainable use of soil moisture resources, high-quality and sustainable management of forest and grass, and high-quality produce of fruit and crop in desert regions.

\section{Acknowlegement}

This research was supported by the National Science Fund of China (Project Nos 42077079,41071193 and 41271539) and Study on high quality sustainable development of soil and moisture conservation (A2180021002)

\section{References}

Budagovski, A.I. 1986. Soil water resources and available water supply of the vegetation cover, Water resources. 12(4):317-325

Cohen. J.E. 1995. Population growth and earth's human carrying capacity. Science. $269,341-346$.

Guo, Z.S., Shao, M.A., Zhang, Y.P. and Wu, Q.X.2002. A Layer-dividing method to soil water in forest land, Proceedings of soil physics and ecological environment construction, edited by Shao MA, Shaanxi Science and technology press, Xian.75-79

Guo, Z.S., Shao, M.A.2003. Carrying capacity of soil water for Vegetation in the Loess Plateau, In: Water-saving agriculture and sustainable use of water and land resources. Shaanxi Science and Technology Press. 704-11.

Guo, Z.S., 2004. Vegetation Carrying Capacity for Soil Water in A Semi-arid Region of Loess Hilly in the Loess Plateau, Dissertation for Doctoral Degree of Northwest SciTech University of Agriculture and Forestry in 2004.

Guo, Z.S., and Li, Y.L. 2009. Initiation stage to regulate the caragana growth and soil water in the semiarid area of Loess Hilly Region, China. Chin. J. Ecol. 29: 5721 - 29.

Guo, Z.S. 2010. Soil water resource use limit in semi-arid loess hilly area. Chin J Applied Ecol. 21:3029-35.

Guo, Z.S. and Shao, M.A. 2013. Impact of afforestation density on soil and water conservation of the semiarid Loess Plateau. J. SOIL WATER CONSERV. 68, 401-410. 
Guo, Z.S. 2014. Theory and Practice on Soil Water Carrying Capacity for Vegetation. Chinese Science Press: website at www.geobooks.com.cn.

Guo, Z.S. 2020. Estimating Method of Maximum Infiltration Depth and Soil Water Supply. Scientific Reports volume 10, (2020) 10:9726| https://doi.org/10.1038/s41598-02066859-0

Guo, Z. S. Soil Water Carrying Capacity for Vegetation. land degradation development.2021. http://DOI: 10.1002/LDR.3950

Lvovich, M. I. 1980. Soil trend in hydrology. Hydrological Sciences Bulletin. 25,33-45

Price, D. 1999.Carrying capacity reconsidered. POPUL ENVIRO. 21, 5-26.

Romano, N.2014. Soil moisture at local scale: Measurements and simulations. J. Hydrol. 516, 6-20.

Steiguer, J. E. D. 1995.Three theories from economics about the environment. Bioscience. 45, 552-557.

Young, C. C. 1998.Defining the range: The development of carrying capacity in management. J. HIST BIOL. 31, 61-83. 